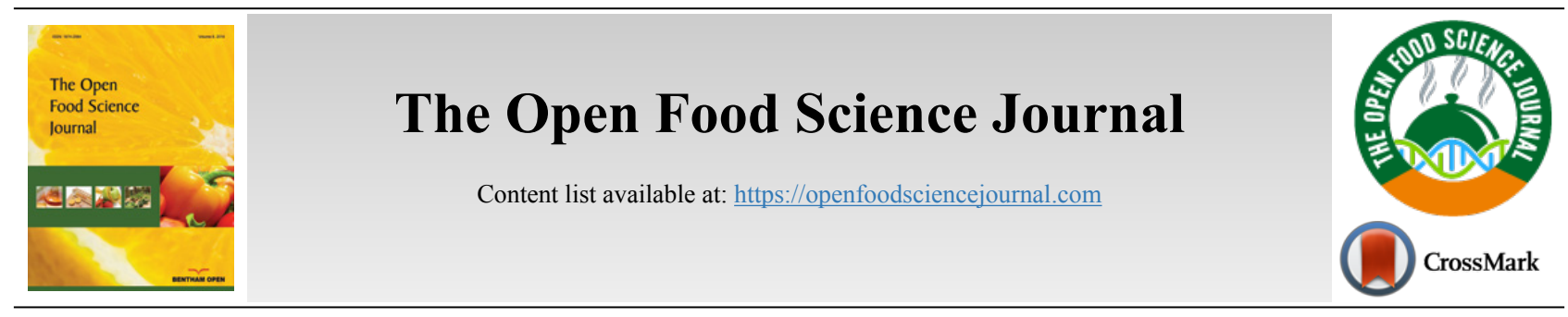

EDITORIAL

\title{
The Rediscovery of Donkey's Milk as Healthy Food for Different Life Stages
}

\author{
Mina Martini ${ }^{1,0, *}$ \\ ${ }^{I}$ Department of Veterinary Science, University of Pisa, Pisa, Italy \\ "Interdepartmental Research Center Nutrafood "Nutraceuticals and Food for Health”, University of Pisa, Pisa, Italy
}

As a member of the editorial advisory board, I would like to draw the Open Food Science Journal readers' attention to the rediscovery of donkey milk in Europe and in the Mediterranean area.

Donkey milk has been traditionally used by humans since ancient times. Nowadays, it is being increasingly studied and the number of papers published on main academic databases (Scopus; ISI; Web of Knowledge) more than tripled in the last ten years; about one-third of these articles come from Europe. The interest for this milk is associated with an increase in the number of dairy farms and an increase in consistency of some donkey breeds that in the past suffered a critical decrease in numbers. Currently, donkey milk is directly sold on the farm as raw milk or is available on the market as pasteurized, UHT, and milk powder. There are also several registered patents related to donkey milk powders, fermented product, and cosmetic preparations.

This milk has gained scientific interest due to the use in the feeding of the increasing number of children who suffer from cows' milk protein allergy (CMPA). These allergic children must exclude cow's milk from their diet; thus they use specific formulas or vegetable beverages. Some of these products still have an allergenic potential or need to be integrated. Other ones do not have a pleasant taste and are therefore rejected by the babies. Donkey's milk has been found to be an adequate alternative for tolerability in allergic children [1] Tolerability is linked to the lower casein content compared to ruminant milks (about $50 \%$ of the total protein) that give soft clot in the stomach and contribute to a better degradability. A high in vitro donkey casein digestibility also seems to play an important role since food protein allergenicity is linked to the survival of the allergen in the gastrointestinal tract. Another reason for the success of donkey milk in the baby diet is its good taste linked to the richness in lactose, about $7 \mathrm{~g} / 100 \mathrm{ml}$.

* Address correspondence to this author at the Department of Veterinary Science, University of Pisa, Pisa, Italy; E-mail: mina.martini@unipi.it
Some concerns regard the nutritional properties of donkey milk in unweaned children, in fact the low fat gives donkey milk lower energy value compared to other milks (e.g. about $360 \mathrm{kcal} / \mathrm{L}$ in donkey vs 640 of bovine milk). However, recent investigations [2] indicate that this limit can be successfully overcome using nutritional supplements (e.g. extra virgin olive oil, medium-chain triglycerides).

The nutritional similarities with human milk, the gold standard for infant feeding, are also encouraging for other uses in children diet. Recently, a fortifier derived from donkey milk for preterm infants (which have suboptimal actual protein intake from breast milk) has been developed [3].

Donkey milk would also have a potential of use in patients suffering from dyslipidemie and obesity. In fact, evidence in animal models showed that donkey milk lowers blood glucose and triglycerides compared to cow milk [4].In addition, the low quantity of energy, fat (lower than $1 \%$ ), and the supply of $n 3$ ALA fatty acid $(0.38 \mathrm{~g} / \mathrm{L}$ of milk) make this milk potentially applicable in low-calorie diets [5].

The high content of vitamin D [5]. makes donkey milk helpful (together with appropriate integrations) for people at risk of vitamin D deficiency (e.g. elderly people).

In vitro activity of donkey milk has been found against bacteria, yeast, and zoonotic dermatophytes [6] these properties would make donkey milk a means to improve human health and of interest also for the natural healthcare industry. Donkey milk is also exploited in the production of dairy products (e.g. yoghurt, ice cream, cheese).

So far, the studies carried out on donkey milk show that it can be considered as a promising functional food. It is also suitable for making dairy products intended for different categories of consumers. Benefits of donkey milk on metabolism should still be more deeply investigated by further clinical studies in humans. 


\section{REFERENCES}

[1] Barni S, Sarti L, Mori F, et al. Tolerability and palatability of donkey's milk in children with cow's milk allergy. Pediatr Allergy Immunol 2018; 29(3): 329-31.

[http://dx.doi.org/10.1111/pai.12871] [PMID: 29392769]

[2] Sarti L, Martini M, Brajon G, et al. Donkey's Milk in the Management of Children with Cow's Milk protein allergy: Nutritional and hygienic aspects. Ital J Pediatr 2019; 45(1): 102. [http://dx.doi.org/10.1186/s13052-019-0700-4] [PMID: 31420060]

[3] Bertino E, Cavallarin L, Cresi F, et al. A Novel Donkey Milk-derived Human Milk Fortifier in Feeding Preterm Infants: A Randomized
Controlled Trial. J Pediatr Gastroenterol Nutr 2019; 68(1): 116-23. [http://dx.doi.org/10.1097/MPG.0000000000002168] [PMID: 30320665]

[4] Trinchese G, Cavaliere G, Canani RB, et al. Human, donkey and cow milk differently affects energy efficiency and inflammatory state by modulating mitochondrial function and gut microbiota. J Nutr Biochem 2015; 26(11): 1136-46.

[http://dx.doi.org/10.1016/j.jnutbio.2015.05.003] [PMID: 26118693]

[5] Martini M, Altomonte I, Licitra R, Salari F. Nutritional and nutraceutical quality of donkey milk. J Equine Vet Sci 2018; 65: 33-7. [http://dx.doi.org/10.1016/j.jevs.2017.10.020]

[6] Altomonte I, Nardoni S, Mancianti F, et al. Preliminary results on antifungal activity of donkey milk. Large Anim Rev in press

\section{(C) 2019 Mina Martini.}

This is an open access article distributed under the terms of the Creative Commons Attribution 4.0 International Public License (CC-BY 4.0), a copy of which is available at: (https://creativecommons.org/licenses/by/4.0/legalcode). This license permits unrestricted use, distribution, and reproduction in any medium, provided the original author and source are credited. 